\title{
Clinical Performance of Human Papillomavirus (HPV) Testing versus Cytology for Cervical Cancer Screening: Results of a Large Danish Implementation Study
}

This article was published in the following Dove Press journal: Clinical Epidemiology

Louise T Thomsen (D)

Susanne K Kjær $\mathbb{D}^{1,2}$

Christian Munk'

Kirsten Frederiksen ${ }^{3}$

Dorthe Ørnskov ${ }^{4}$

Marianne Waldstrøm ${ }^{4,5}$

'Unit of Virus, Lifestyle and Genes, Danish Cancer Society Research Center, Copenhagen, Denmark; ${ }^{2}$ Department of Gynecology, Copenhagen University Hospital Rigshospitalet, Copenhagen, Denmark; ${ }^{3}$ Unit of Statistics and Pharmacoepidemiology, Danish Cancer Society Research Center, Copenhagen, Denmark; ${ }^{4}$ Department of Pathology, Vejle Hospital, Lillebaelt Hospital, Region of Southern Denmark, Vejle, Denmark; ${ }^{5}$ Institute of Regional Health Research, University of Southern Denmark, Odense, Denmark
Correspondence: Louise T Thomsen Unit of Virus, Lifestyle and Genes,

Danish Cancer Society Research

Center, Strandboulevarden 49,

Copenhagen DK-2100, Denmark

Tel +4535257927

Email Itt@cancer.dk
Background: Human papillomavirus (HPV) testing is increasingly used as the primary cervical cancer screening test. In a large pilot implementation, we compared participation, referrals and detection of high-grade cervical intraepithelial neoplasia (CIN) in HPV- versus cytology-based cervical cancer screening.

Methods: The implementation was embedded into the routine screening program at Lillebaelt Hospital, Department of Pathology, Vejle, Denmark. Based on the area of residence, women aged 30-59 years were screened by either HPV testing (with HPV16/18 genotyping and cytology triage) or cytology (with HPV triage for minor abnormalities). Our analysis includes women invited or screened during May 2017-May 2018 (invited: $n=35,081$; screened: $n=28,352$ ) with 6 months of follow-up. Information on screening results and sociodemographic characteristics were obtained from registers. Using logistic regression, we estimated odds ratios (ORs) with 95\% confidence intervals (CIs) of participation, referral and CIN3+-detection in HPV- versus cytology-based screening, adjusting for sociodemographic characteristics.

Results: Participation was virtually identical in the HPV- and cytology group (58.4\% vs $58.8 \%$; $\left.\mathrm{OR}_{\text {adjusted }}=0.97,95 \% \mathrm{CI}, 0.93-1.01\right)$. Referral to colposcopy was more common in the HPV- than cytology group (3.8\% vs $2.1 \%$; $\left.\mathrm{OR}_{\text {adjusted }}=1.88,95 \% \mathrm{CI}, 1.63-2.17\right)$. More cases of CIN3+ were detected in the HPV- than cytology group (1.0\% vs $0.7 \%$, $\left.\mathrm{OR}_{\text {adjusted }}=1.47 ; 95 \% \mathrm{CI}, 1.13-1.91\right)$.

Conclusion: Participation did not differ between HPV- and cytology-based screening. HPVbased screening detected more cases of $\mathrm{CIN} 3+$, but in this initial screening round also led to more colposcopies than cytology-based screening.

Keywords: human papillomavirus, cervical cancer, cervical intraepithelial neoplasia, screening, HPV testing, cytology, secondary prevention

\section{Introduction}

Screening for cervical cancer using cervical cytology has reduced the incidence of this disease in many countries. ${ }^{1}$ Randomised trials have shown that testing for high-risk human papillomavirus (HPV) is more sensitive than cytology in detecting high-grade cervical intraepithelial neoplasia $(\mathrm{CIN}) .^{2-8}$ Therefore, HPV-based screening can prevent more cervical cancers. ${ }^{9}$ HPV testing is, however, less specific than cytology. ${ }^{10}$

Several countries are currently implementing HPV-based screening for women aged $>25-35$ years. ${ }^{11-17}$ On this basis, data on the performance of HPV-based screening in 
a real-world clinical setting, in contrast to a randomised research setting, are beginning to emerge. ${ }^{12,15,18-28}$ However, only few of these studies compared HPV-based screening with a contemporary control group screened by cytology. ${ }^{12,18,19}$

In Denmark, national guidelines recommend screening every 3 years in women aged 23-49 and every 5 years in women aged 50-64. ${ }^{29}$ Women aged $23-59$ years are screened by cytology, while HPV-based primary screening is only recommended for women aged 60-64. ${ }^{29}$ A National Steering Group for Cervical Cancer Screening was established in 2018 to plan a gradual implementation of HPV-based screening for women aged $30-59 .{ }^{30}$ However, currently, no Danish data are available to inform these implementation efforts.

In 2017, we initiated the first Danish pilot implementation of HPV-based screening. This paper presents the first results from the pilot. We aimed to compare participation, proportions of unsatisfactory screening tests, colposcopy referrals and detection of high-grade CIN and cervical cancer in women screened with HPV testing compared with cytology.

\section{Methods}

\section{Organization of Screening}

Cervical cancer screening in Denmark is organized by the five regions that are responsible for implementing the screening guidelines from the National Board of Health. Screening is free of charge, and smears are obtained by general practitioners or gynecologists. A nationwide register, the Pathology Databank, contains information on screening invitations, reminders, and all cervical cytologies, biopsies, cones and hysterectomies. The register is virtually complete from the mid-1990es, but most pathology departments have added historical data dating back to the 1970 es. ${ }^{31}$ Women are invited for screening if they do not have a screening sample registered within the recommended interval. Women who do not participate receive reminders 90 and 180 days after the invitation. ${ }^{29,32}$

\section{Design and Study Population}

HPV SCREEN DENMARK is a real-word implementation study embedded into the routine screening program at the Department of Pathology, Vejle Hospital, Lillebaelt Hospital, Region of Southern Denmark. This department processes around 50,000 cervical cytology samples annually (approximately $12 \%$ of all smears in Denmark). ${ }^{32}$ The implementation targets women aged 30-59 years residing in the department's uptake area. During the implementation, women are offered HPV- or cytology-based screening depending on the municipality of residence. Women residing in four municipalities (Vejle, Fredericia, Kolding, Middelfart) are offered HPV-based screening, while women residing in nine other municipalities (Assens, Faaborg-Midtfyn, Kerteminde, Nyborg, Odense, Svendborg, Nordfyns, Langeland, Ærø) are offered cytology-based screening. The screening invitations describe the screening method offered to each woman. The choice of municipalities for each screening method was made to achieve an approximate $40-60 \%$ distribution of women in the HPV- and cytology groups and was also based on administrative considerations relating to different IT- and invitation systems in the two geographical areas. Before initiation of the implementation, general practitioners and gynecologists in the region were informed about the study at meetings, by e-mail and through a webpage.

HPV-based screening was initiated on 29 May 2017. In this paper, the analysis of participation included women invited during the first year $(n=35,081)$. The analysis of referral rates and high-grade CIN detection included women screened during the first year $(n=28,352)$, including women screened after invitation and those screened at their own initiative.

\section{Ethics}

The study was considered by the Ethics Committee in the Region of Southern Denmark to be an implementation project in clinical practice exempt from informed consent (S-20160146). The study was approved by the Data Protection Agency in the Region of Southern Denmark (18/21475) and the National Board of Patient Safety (3-3013-2597).

\section{Sample Collection and Processing}

Liquid-based cytology samples (ThinPrep, Hologic) were collected by general practitioners or gynecologists and sent to Vejle Pathology Department for processing. HPV DNA testing was performed using the Cobas HPV test (Roche) providing individual detection of HPV16 and 18, and pooled detection of 12 other oncogenic HPV types $(31,33,35,39,45,51,52,55$, $56,58,66,68)$. HPV mRNA testing was performed using the Aptima HPV mRNA test (Hologic) which detects E6/E7 mRNA of 14 oncogenic HPV types $(16,18,31,33,35,39,45,51$, 52,55,56,58,66,68). Cytologic diagnoses were classified according to the 2001 Bethesda classification. Slides were read by biotechnicians, and abnormal diagnoses were confirmed by a pathologist. 


\section{Clinical Management}

Figure 1 shows the screening algorithms. In the HPV group, women with HPV16/18 were referred to colposcopy. Women with 12 other oncogenic HPV types received cytology triage. If they had atypical squamous cells of undetermined significance (ASCUS) or worse, they were referred to colposcopy, and if they had normal cytology, they were invited for repeat screening after a year. Cytology was read with knowledge of HPV status. In the cytology group, women were managed according to national guidelines. ${ }^{29}$ Women with high-grade squamous intraepithelial lesions (HSIL), atypical squamous cells cannot exclude HSIL, atypical glandular cells or adenocarcinoma in situ (AIS) were referred to colposcopy. Women with low-grade squamous intraepithelial lesions (LSIL) were tested for HPV mRNA, and HPV mRNA positive women were referred to colposcopy, while HPV mRNA negative women were invited for repeat screening after a year. Women with ASCUS were tested for HPV DNA, and HPV DNA positive women were referred to colposcopy, while HPV DNA negative women returned to routine screening.

Colposcopy was performed in routine practice by private or hospital-based gynecologists. Danish guidelines recommend that colposcopy-guided biopsies are supplemented with random biopsies from quadrants without visible changes. ${ }^{33}$ The vast majority of histologies were evaluated at pathology departments in the Region of Southern Denmark (Vejle Pathology Department: 50\%; Odense Pathology Department: 49\%), whereas 1\% were evaluated at other pathology departments in the country. Histological diagnoses were classified according to the CIN nomenclature. In the analysis, CIN grade 2 or worse (CIN2+) included histological diagnoses of CIN2, CIN3,

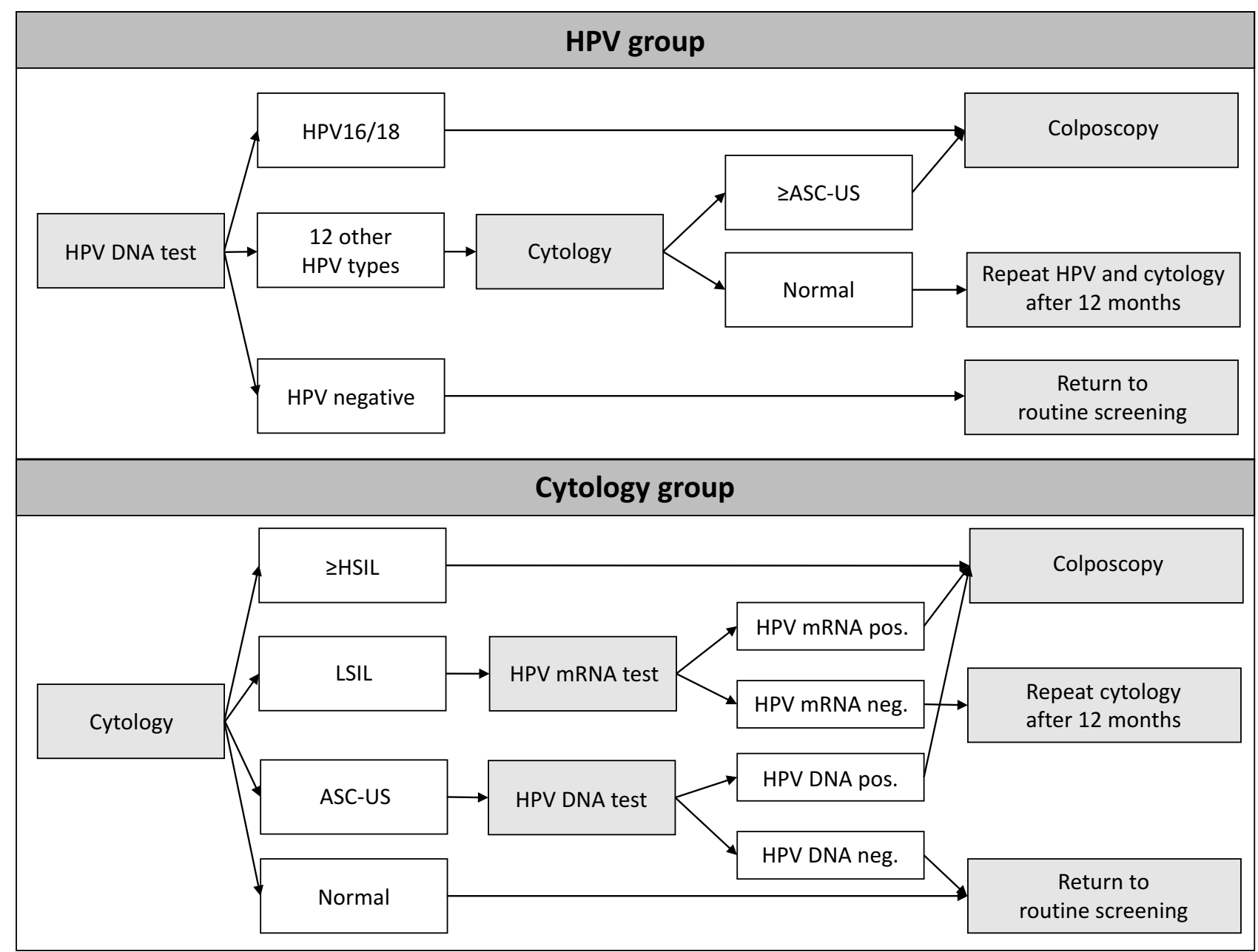

Figure I Screening algorithms in the HPV- and cytology group of HPV SCREEN DENMARK.

Abbreviations: ASC-US, atypical squamous cells of undetermined significance; DNA, deoxyribonucleic acid; HPV, human papillomavirus; HSIL, high-grade squamous intraepithelial lesion; LSIL, low-grade squamous intraepithelial lesion; mRNA, messenger ribonucleic acid. 
AIS and cervical cancer, and CIN grade 3 or worse (CIN3+) included CIN3, AIS and cervical cancer.

\section{Registry Linkages}

All residents in Denmark have a unique personal identification number which is used in all national registries. Using this personal identification number, we retrieved information from the Pathology Databank on screening invitations, cervical cytological and histological diagnoses and HPV results. Information from the Pathology Databank was available until 27 Nov 2018, ie all women had at least 6 months' follow-up from the screening date. Furthermore, we retrieved individual-level data on educational level, employment and country of origin from registries in Statistics Denmark, ${ }^{34,35}$ and information on individual HPV vaccination status from the National Prescription Register ${ }^{36}$ and the National Health Service Register. ${ }^{37}$

\section{Statistical Analysis}

In the analysis of screening participation, baseline was defined as the date of first screening invitation during the study. We used Kaplan-Meier's method to estimate the probability of participation by time since the invitation. Logistic regression was used to estimate odds ratios (ORs) with $95 \%$ confidence intervals (CIs) of participation within 6 months of invitation in the HPV- compared with the cytology group. Estimates were reported crude (model 1); adjusted for age, education, country of origin and employment (model 2); and further adjusted for HPV vaccination, previous history of CIN2+, and whether or not the woman was screened in the previous round (model 3). Adjustment variables were selected à priori.

In the analysis of referrals and detection of CIN $2+/ \mathrm{CIN} 3+$, baseline was defined as the date of the first screening test during the study. We calculated the proportion of women with unsatisfactory screening tests, and the proportions referred to colposcopy or repeat screening at baseline. Furthermore, we calculated the proportion of women with CIN2+ or CIN3+ diagnosed within 6 months. This analysis included $\mathrm{CIN} 2+/ \mathrm{CIN} 3+$ diagnosed as a result of clinical follow-up after the baseline screen, whereas the results of followup after repeat testing at 12 months were not yet available. Logistic regression was performed to assess ORs of unsatisfactory tests, colposcopy, repeat screening and detection of CIN2+/CIN3+ in the HPV versus cytology group. Furthermore, we calculated the positive predictive value (PPV) of colposcopy referral as the proportion of women with CIN2+/CIN3+ among those referred to colposcopy. We did not calculate the negative predictive value, because $<3 \%$ of the women with a negative screening test (HPV negative or normal cytology) had a cervical cytology or histology within the 6-month follow-up period in the study.

\section{Results}

\section{Screening Participation}

We invited 35,081 women for screening during the first year (HPV group: $\mathrm{n}=14,104$; cytology group: $\mathrm{n}=20,977)$. The age distribution was similar in women invited for HPV- and cytology-based screening (median, 43 years; interquartile range [IQR], 37-49 years). Women invited for HPV-based screening were slightly more likely than those invited for cytology-based screening to be employed (77.6\% vs $73.4 \%$ ). All other characteristics were similar in the two groups (Table 1).

At 6 months after invitation, participation was virtually identical in women invited for HPV- and cytology-based screening (58.4\% [95\% CI, 57.6-59.2\%] versus 58.8\% [95\% CI, 58.1-59.4\%]). The same pattern was seen 1 year after invitation $(69.9 \%$ [95\% CI, 69.1-70.7\%] versus 70.0\% [95\% CI, 69.3-70.6\%]) (Supplementary Figure S1).

The odds of participation did not differ in women invited for HPV- compared with cytology-based screening, neither in the crude model $\left(\mathrm{OR}_{\text {crude }}=0.99\right.$, 95\% CI, 0.94-1.03) or when adjusting for sociodemographic characteristics $\left(\mathrm{OR}_{\text {adj. }}=0.97,95 \% \mathrm{CI}, 0.93-\right.$ 1.01) (Table 2). There were no statistically significant differences in participation between HPV and cytologybased screening at any age. When we additionally adjusted for HPV vaccination, history of CIN2+, and previous screening participation, OR estimates were virtually identical (data not shown).

\section{Referrals and Histological Outcomes}

A total of 28,352 women were screened during the first year (HPV group: $\mathrm{n}=11,339$; cytology group: $\mathrm{n}=17,013)$. Of these, 21,268 (75.0\%) had been invited for screening within a year before the screening date (HPV group: 71.5\%; cytology group: 77.3\%), whereas the remaining women had not been invited within the past year. The median age was 43 (IQR, 37-49) in the HPV group and 44 (IQR, 37-50) in the cytology group. A slightly higher proportion in the HPV than cytology group were employed ( $81.4 \%$ vs $77.4 \%)$. Other characteristics were similar in the two groups (Table 1). 
Table I Characteristics of Women in HPV and Cytology Groups in the HPV SCREEN DENMARK Study

\begin{tabular}{|c|c|c|c|c|c|c|c|c|}
\hline \multirow[t]{4}{*}{ Characteristic } & \multicolumn{4}{|c|}{ A. Invited population $(n=35,08 I)$} & \multicolumn{4}{|c|}{ B. Screened population $(n=28,352)$} \\
\hline & \multirow{2}{*}{\multicolumn{2}{|c|}{$\begin{array}{l}\text { HPV group } \\
(n=\mid 4,104)\end{array}$}} & \multirow{2}{*}{\multicolumn{2}{|c|}{$\begin{array}{c}\text { Cytology group } \\
(n=20,977)\end{array}$}} & \multirow{2}{*}{\multicolumn{2}{|c|}{$\begin{array}{c}\text { HPV group } \\
(n=\mid, 339)\end{array}$}} & \multirow{2}{*}{\multicolumn{2}{|c|}{$\frac{\text { Cytology group }}{(n=17,013)}$}} \\
\hline & & & & & & & & \\
\hline & $\mathbf{n}$ & $\%$ & $\mathbf{n}$ & $\%$ & $\mathbf{n}$ & $\%$ & $\mathbf{n}$ & $\%$ \\
\hline \multicolumn{9}{|l|}{$\mathrm{Age}^{\mathrm{a}}$} \\
\hline $30-34$ & 2,190 & 15.5 & 3,196 & 15.2 & $\mathrm{I}, 705$ & 15.0 & 2,685 & 15.8 \\
\hline $35-39$ & 2,609 & 18.5 & 3,791 & 18.1 & 2,065 & 18.2 & 3,005 & 17.7 \\
\hline $40-44$ & 3,097 & 22.0 & 4,345 & 20.7 & 2,429 & 21.4 & 3,440 & 20.2 \\
\hline $45-49$ & 3,093 & 21.9 & 4,589 & 21.9 & 2,378 & 21.0 & 3,601 & 21.2 \\
\hline $50-54$ & 1,462 & 10.4 & 2,430 & 11.6 & 1,493 & 13.2 & 2,230 & 13.1 \\
\hline $55-59$ & 1,653 & 11.7 & 2,626 & 12.5 & 1,269 & 11.2 & 2,052 & 12.1 \\
\hline Median (IQR) & \multicolumn{2}{|c|}{43 (37-49) } & \multicolumn{2}{|c|}{$43(37-49)$} & \multicolumn{2}{|c|}{$43(37-49)$} & \multicolumn{2}{|c|}{$44(37-50)$} \\
\hline \multicolumn{9}{|l|}{ Educational level } \\
\hline Basic & 2,228 & 15.8 & 3,438 & 16.4 & 1,510 & 13.3 & 2,356 & 13.8 \\
\hline Medium & 5,560 & 39.4 & 8,332 & 39.7 & 4,443 & 39.2 & 6,727 & 39.5 \\
\hline High & 6,001 & 42.5 & 8,831 & 42.1 & 5,247 & 46.3 & 7,752 & 45.6 \\
\hline Missing & 315 & 2.2 & 376 & 1.8 & 139 & 1.2 & 178 & 1.0 \\
\hline \multicolumn{9}{|l|}{ Country of origin } \\
\hline Denmark & 11,994 & 85.0 & 17,835 & 85.0 & 9,911 & 87.4 & 14,918 & 87.7 \\
\hline Immigrant & 1,965 & 13.9 & 2,925 & 13.9 & 1,362 & 12.0 & 2,005 & 11.8 \\
\hline Descendant & 56 & 0.4 & 115 & 0.5 & 46 & 0.4 & 75 & 0.4 \\
\hline Missing & 89 & 0.6 & 102 & 0.5 & 20 & 0.2 & 15 & 0.1 \\
\hline \multicolumn{9}{|l|}{ Employment } \\
\hline Employed & 10,945 & 77.6 & 15,403 & 73.4 & 9,232 & 81.4 & 13,176 & 77.4 \\
\hline Unemployed & 2,824 & 20.0 & 5,006 & 23.9 & 1,905 & 16.8 & 3,428 & 20.1 \\
\hline Students & 239 & 1.7 & 454 & 2.2 & $|8|$ & 1.6 & 389 & 2.3 \\
\hline Missing & 96 & 0.7 & 114 & 0.5 & 21 & 0.2 & 20 & 0.1 \\
\hline \multicolumn{9}{|l|}{ HPV vaccinated } \\
\hline Yes & 1,234 & 8.8 & 1,915 & 9.1 & $\mathrm{I}, 247$ & 11.0 & 1,928 & 11.3 \\
\hline No & 12,870 & 91.3 & 19,062 & 90.9 & 10,092 & 89.0 & 15,085 & 88.7 \\
\hline \multicolumn{9}{|c|}{ Screened in previous screening round ${ }^{b}$} \\
\hline Yes & 11,103 & 78.7 & 16,616 & 79.2 & 9,904 & 87.3 & 14,788 & 86.9 \\
\hline No & 3,001 & 21.3 & 4,361 & 20.8 & $\mathrm{I}, 435$ & 12.7 & 2,225 & 13.1 \\
\hline \multicolumn{9}{|c|}{ History of cervical dysplasia } \\
\hline No prior CIN2+ & 13,249 & 93.9 & 19,660 & 93.7 & 10,322 & 91.0 & 15,584 & 91.6 \\
\hline Prior $\mathrm{CIN} 2+$ & 855 & 6.1 & 1,317 & 6.3 & 1,017 & 9.0 & 1,429 & 8.4 \\
\hline
\end{tabular}

Notes: a For invited population: age at invitation; For screened population: age at screening. ${ }^{b}$ For women aged $30-49$ years: Screened during the past 4 years; For women aged 50-59 years: Screened during the past 6 years.

Abbreviations: CIN2+, cervical intraepithelial neoplasia grade 2 or worse; HPV, human papillomavirus, IQR, interquartile range.

Figure 2 provides an overview of baseline referrals and histological outcomes during up to 6 months. Of those referred to colposcopy, 92\% (403/436) in the HPV group and $98 \%(354 / 362)$ in the cytology group had a histology during follow-up. Few histological samples were taken outside protocol, ie among those referred to 12 -month repeat (HPV group: $36 / 566=6.4 \%$; cytology group: $1 / 30=3.3 \%$ ) or routine screening (HPV group: 278/10,329=2.7\%; cytology group: $415 / 16,504=2.5 \%$ ). In the HPV group, we observed 51 CIN2 cases, 93 CIN3 cases, 12 AIS cases and 5 cancers (3 squamous cell carcinomas and 2 adenocarcinomas). In the cytology group, we observed 41 CIN2 cases, 104 CIN3 cases, 6 AIS cases and 7 cancers ( 5 squamous cell carcinomas and 2 adenocarcinomas). 
Table 2 Odds Ratio of Screening Participation Within Six Months of Invitation in HPV Group and Cytology Group, Overall and by Age

\begin{tabular}{|c|c|c|c|c|c|c|c|c|}
\hline \multirow[t]{2}{*}{ Age } & \multirow[t]{2}{*}{ Group } & \multirow[t]{2}{*}{ N Invited for Screening } & \multicolumn{2}{|c|}{ n (\%) Screened } & \multicolumn{2}{|c|}{ Model I (Crude) } & \multicolumn{2}{|c|}{ Model 2 (Adjusted*) } \\
\hline & & & & & OR & $(95 \% \mathrm{Cl})$ & OR & $(95 \% \mathrm{Cl})$ \\
\hline All & $\begin{array}{l}\text { Cytology } \\
\text { HPV }\end{array}$ & $\begin{array}{l}20,977 \\
14,104\end{array}$ & $\begin{array}{l}\mid 2,327 \\
824 \mid\end{array}$ & $\begin{array}{l}(58.8) \\
(58.4)\end{array}$ & $\begin{array}{l}1 \\
0.99\end{array}$ & $\begin{array}{l}\text { (ref) } \\
(0.94-1.03)\end{array}$ & $\begin{array}{l}1 \\
0.97\end{array}$ & $\begin{array}{l}\text { (ref) } \\
(0.93-1.01)\end{array}$ \\
\hline $30-39$ & $\begin{array}{l}\text { Cytology } \\
\text { HPV }\end{array}$ & $\begin{array}{l}6987 \\
4799\end{array}$ & $\begin{array}{l}3703 \\
2477\end{array}$ & $\begin{array}{l}(53.0) \\
(51.6)\end{array}$ & $\begin{array}{l}1 \\
0.95\end{array}$ & $\begin{array}{l}\text { (ref) } \\
(0.88-1.02)\end{array}$ & $\begin{array}{l}1 \\
0.93\end{array}$ & $\begin{array}{l}\text { (ref) } \\
(0.86-1.00)\end{array}$ \\
\hline $40-49$ & $\begin{array}{l}\text { Cytology } \\
\text { HPV }\end{array}$ & $\begin{array}{l}8934 \\
6190\end{array}$ & $\begin{array}{l}5405 \\
3800\end{array}$ & $\begin{array}{l}(60.5) \\
(61.4)\end{array}$ & $\begin{array}{l}1 \\
1.04\end{array}$ & $\begin{array}{l}\text { (ref) } \\
(0.97-I . I I)\end{array}$ & $\begin{array}{l}1 \\
1.01\end{array}$ & $\begin{array}{l}\text { (ref) } \\
(0.95-1.09)\end{array}$ \\
\hline $50-59$ & $\begin{array}{l}\text { Cytology } \\
\text { HPV }\end{array}$ & $\begin{array}{l}5056 \\
3115\end{array}$ & $\begin{array}{l}3219 \\
1964\end{array}$ & $\begin{array}{l}(63.7) \\
(63.0)\end{array}$ & $\begin{array}{l}\text { I } \\
0.97\end{array}$ & $\begin{array}{l}\text { (ref) } \\
(0.89-1.07)\end{array}$ & $\begin{array}{l}1 \\
0.95\end{array}$ & $\begin{array}{l}\text { (ref) } \\
(0.86-1.05)\end{array}$ \\
\hline
\end{tabular}

Notes: *Adjusted for age, educational level, country of origin and employment status. A total of 691 women (2.0\%) with missing values of adjustment variables excluded from model.

Abbreviations: $\mathrm{Cl}$, confidence interval; HPV, human papillomavirus; OR, odds ratio.

Fewer women in the HPV (0.1\%) than cytology group $(0.7 \%)$ had an unsatisfactory screening test $\left(\mathrm{OR}_{\text {crude }}=0.10\right.$; 95\% CI, 0.05-0.21) (Table 3). Of the eight women with unsatisfactory screening tests in the HPV group, four had an invalid HPV result while four had unsatisfactory cytology triage (data not shown). The proportion of women referred to colposcopy was higher in the HPV (3.8\%) than cytology group (2.1\%) $\left(\mathrm{OR}_{\text {crude }}=1.84 ; 95 \% \mathrm{CI}, 1.60-2.12\right)$ (Table 3). The proportion referred to colposcopy decreased with age in both groups. The proportion of women referred to 12-month repeat screening was higher in the HPV $(5.0 \%)$ than cytology group $(0.2 \%)\left(\mathrm{OR}_{\text {crude }}=29.73 ; 95 \% \mathrm{CI}, 20.58-42.96\right)$, and this was seen in all age groups. All OR estimates were virtually unchanged when adjusting for sociodemographic characteristics. Furthermore, all estimates were similar when further adjusting for HPV vaccination, history of $\mathrm{CIN} 2+$, and screening during the past round (data not shown).

The proportion of women with CIN2+ was higher in the HPV (1.4\%) than cytology group $(0.9 \%)\left(\mathrm{OR}_{\text {crude }}=1.54\right.$; 95\% CI, 1.23-1.92) (Table 4). This was seen in all age groups. The proportion of women with $\mathrm{CIN} 3+$ was also higher in the HPV (1.0\%) than cytology group $(0.7 \%)$ $\left(\mathrm{OR}_{\text {crude }}=1.42 ; 95 \% \mathrm{CI}, 1.09-1.84\right)$. When adjusting for sociodemographic characteristics, OR estimates were virtually unchanged. Further adjustment for HPV vaccination, history of CIN2+ and screening during the past round yielded

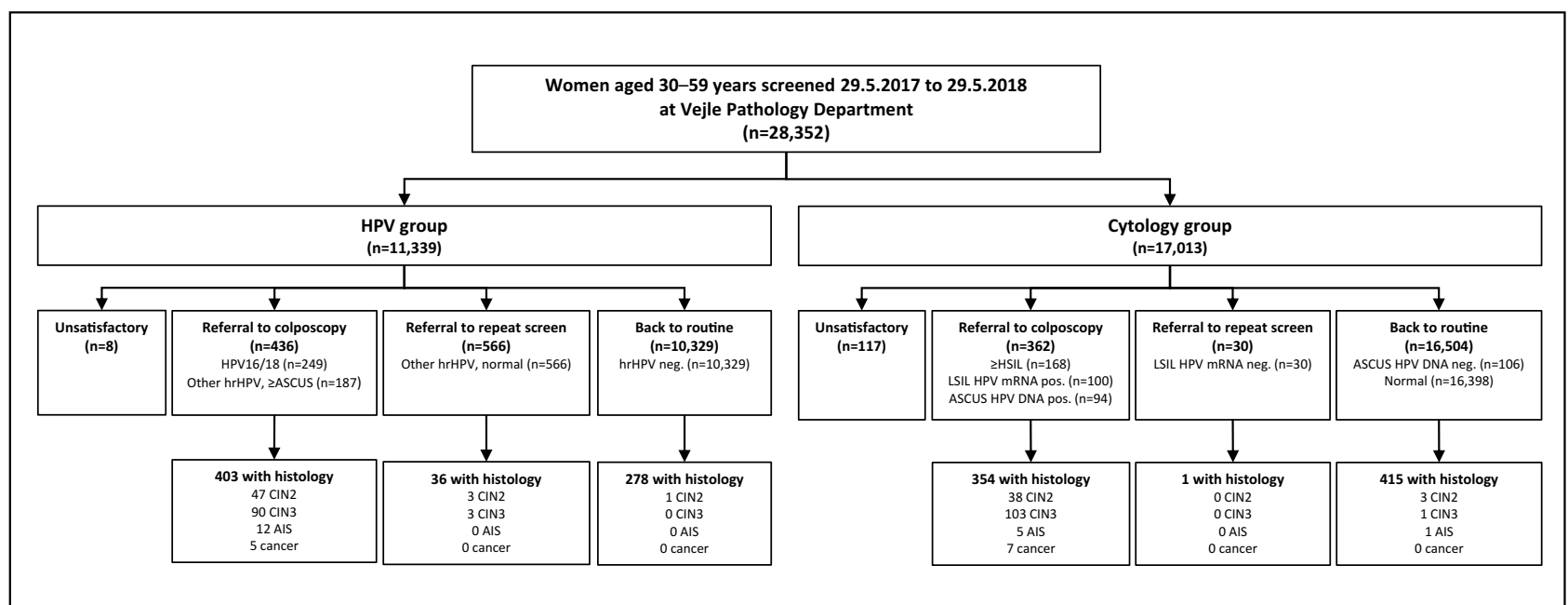

Figure 2 Flowchart of referrals and clinical outcomes among women screened by HPV testing or cytology during year I of the HPV SCREEN DENMARK study. Abbreviations: AIS, adenocarcinoma in situ; ASCUS, atypical squamous cells of undetermined significance; CIN2, cervical intraepithelial neoplasia grade 2; CIN3, cervical intraepithelial neoplasia grade 3; DNA, deoxyribonucleic acid; HPV, human papillomavirus; hrHPV, high-risk human papillomavirus; HSIL, high-grade squamous intraepithelial lesion; LSIL, low-grade squamous intraepithelial lesion; mRNA, messenger ribonucleic acid. 
Table 3 Proportions and Odds Ratios of Referral to Colposcopy, Repeat Screening and Routine Screening in HPV and Cytology Groups, Overall and According to Age

\begin{tabular}{|c|c|c|c|c|c|c|c|c|c|}
\hline \multirow[t]{4}{*}{ Referral at Baseline } & \multirow[t]{4}{*}{ Age } & \multirow{3}{*}{\multicolumn{2}{|c|}{$\begin{array}{l}\text { HPV Group } \\
n=11,339\end{array}$}} & \multirow{3}{*}{\multicolumn{2}{|c|}{$\begin{array}{l}\text { Cytology Group } \\
n=\mid 7,013\end{array}$}} & \multicolumn{4}{|c|}{ OR for HPV versus Cytology Group } \\
\hline & & & & & & \multirow{2}{*}{\multicolumn{2}{|c|}{$\frac{\text { Model I }}{\text { (Crude) }}$}} & \multirow{2}{*}{\multicolumn{2}{|c|}{$\begin{array}{l}\text { Model } 2 \\
\text { (Adjusted*) }\end{array}$}} \\
\hline & & & & & & & & & \\
\hline & & $\mathbf{n}$ & (\%) & $\mathbf{n}$ & (\%) & OR & $(95 \% \mathrm{Cl})$ & OR & $(95 \% \mathrm{Cl})$ \\
\hline \multirow{4}{*}{ New screen due to unsatisfactory test } & All & 8 & $(0.1)$ & 117 & $(0.7)$ & 0.10 & $(0.05-0.21)$ & 0.11 & $(0.05-0.22)$ \\
\hline & $30-39$ & 3 & $(0.1)$ & 47 & $(0.8)$ & 0.10 & $(0.03-0.31)$ & 0.10 & $(0.03-0.33)$ \\
\hline & $40-49$ & 3 & $(0.1)$ & 40 & $(0.6)$ & 0.11 & $(0.03-0.35)$ & 0.11 & $(0.04-0.36)$ \\
\hline & $50-59$ & 2 & $(0.1)$ & 30 & $(0.7)$ & 0.10 & $(0.03-0.43)$ & 0.11 & $(0.03-0.44)$ \\
\hline \multirow[t]{4}{*}{ Colposcopy } & All & 436 & (3.8) & 362 & $(2.1)$ & 1.84 & $(1.60-2.12)$ & 1.88 & $(1.63-2.17)$ \\
\hline & $30-39$ & 199 & $(5.3)$ & 182 & $(3.2)$ & 1.69 & $(1.37-2.07)$ & 1.73 & $(1.4 I-2.13)$ \\
\hline & $40-49$ & 162 & (3.4) & 128 & $(1.8)$ & 1.88 & $(1.49-2.38)$ & 1.94 & $(1.53-2.46)$ \\
\hline & $50-59$ & 75 & $(2.7)$ & 52 & $(1.2)$ & 2.27 & $(1.59-3.25)$ & 2.22 & $(1.55-3.17)$ \\
\hline \multirow[t]{4}{*}{ Repeat screening in 12 months } & All & 566 & $(5.0)$ & 30 & $(0.2)$ & 29.73 & $(20.58-42.96)$ & 29.85 & $(20.65-43.14)$ \\
\hline & $30-39$ & 236 & $(6.3)$ & 12 & $(0.2)$ & 31.59 & $(17.66-56.49)$ & 31.44 & $(17.56-56.28)$ \\
\hline & $40-49$ & 227 & $(4.7)$ & 13 & $(0.2)$ & 26.79 & $(15.30-46.91)$ & 27.11 & $(15.48-47.48)$ \\
\hline & $50-59$ & 103 & $(3.7)$ & 5 & $(0.1)$ & 33.12 & $(|3.48-8| .34)$ & 32.78 & $(13.33-80.63)$ \\
\hline \multirow[t]{4}{*}{ Back to routine screening } & All & 10,329 & (91.I) & 16,504 & $(97.0)$ & 0.32 & $(0.28-0.35)$ & 0.31 & $(0.27-0.34)$ \\
\hline & $30-39$ & 3332 & $(88.4)$ & 5449 & $(95.8)$ & 0.34 & $(0.29-0.40)$ & 0.32 & $(0.28-0.38)$ \\
\hline & $40-49$ & 4415 & (91.8) & 6860 & $(97.4)$ & 0.30 & $(0.25-0.36)$ & 0.29 & $(0.24-0.35)$ \\
\hline & $50-59$ & 2582 & $(93.5)$ & 4195 & $(98.0)$ & 0.30 & $(0.23-0.39)$ & 0.30 & $(0.23-0.39)$ \\
\hline
\end{tabular}

Notes: *Adjusted for age, educational level, country of origin and employment status; 317 women with missing values of adjustment variables excluded from models. Abbreviations: $\mathrm{Cl}$, confidence interval; HPV, human papillomavirus; OR, odds ratio, PPV, positive predictive value.

similar results (data not shown). When we only included cases of CIN2+/CIN3+ diagnosed among women referred to colposcopy ("per protocol-detected" cases), we still found more CIN2+ ( $1.4 \%$ vs $0.9 \%$; $\mathrm{OR}_{\text {crude }}=1.52 ; 95 \% \mathrm{CI}, 1.21-$ $1.90)$ and $\mathrm{CIN} 3+\left(0.9 \%\right.$ vs $0.7 \% ; \mathrm{OR}_{\text {crude }}=1.40 ; 95 \% \mathrm{CI}$, 1.08-1.82) in the HPV than cytology group (data not shown).

The PPV of colposcopy referral was lower in the HPV than cytology group, both for CIN2+ (35.3\% [95\% CI, 30.8-39.8] versus $42.3 \%$ [95\% CI, 37.2-47.4]) and CIN3+ (24.5\% [95\% CI, 20.5-28.6] versus 31.8\% [95\% CI, 26.9-36.6]) (Table 4). The PPV decreased with age in both groups, but was lower for HPV than cytology screening at all ages.

\section{Discussion}

In this large Danish pilot implementation, HPV-based screening provided greater detection of high-grade CIN than cytology-based screening. This is in line with the findings of randomised trials ${ }^{2-8}$ and supports the higher sensitivity of HPV testing than cytology. Moreover, our finding is in line with previous implementation studies from England, ${ }^{12}$ Netherlands, ${ }^{28}$ Italy ${ }^{21,22,25}$ and Finland. ${ }^{18}$ In our study, the CIN3+ detection was $40-50 \%$ higher in the HPV than cytology group. Notably, this improved detection was seen already after 6 months of follow-up, without including the additional cases of CIN2-3 that may be detected after 12month repeat screening of women with non-HPV16/18 oncogenic HPV and normal cytology at baseline.

Our analysis also showed that HPV screening resulted in more colposcopy referrals at baseline than cytology, in line with previous results. ${ }^{12,18,21,22,25,28}$ Excessive colposcopy referrals are problematic because they may lead to overtreatment of regressive CIN $2,{ }^{4}$ and CIN treatment may increase the risk of pregnancy-related morbidity. ${ }^{38}$ In our study, approximately $80 \%$ more women were referred to immediate colposcopy in the HPV than cytology group (3.8\% versus $2.1 \%)$. Our referral rate in the HPV group (3.8\%) was similar to the baseline referral rate in the English pilot (4.2\%), ${ }^{12}$ but slightly higher than in the Dutch HPV-based screening program $(3.0 \%) .{ }^{28}$ In our study, we used a highly sensitive HPV-based screening strategy, referring all women with HPV16/18 regardless of cytology. This corresponds to algorithms in the USA $^{39}$ and Australia, ${ }^{16}$ whereas most European countries only refer HPV-positive women with abnormal cytology. ${ }^{12,15,18,19,28}$ In the cytology group, we employed 


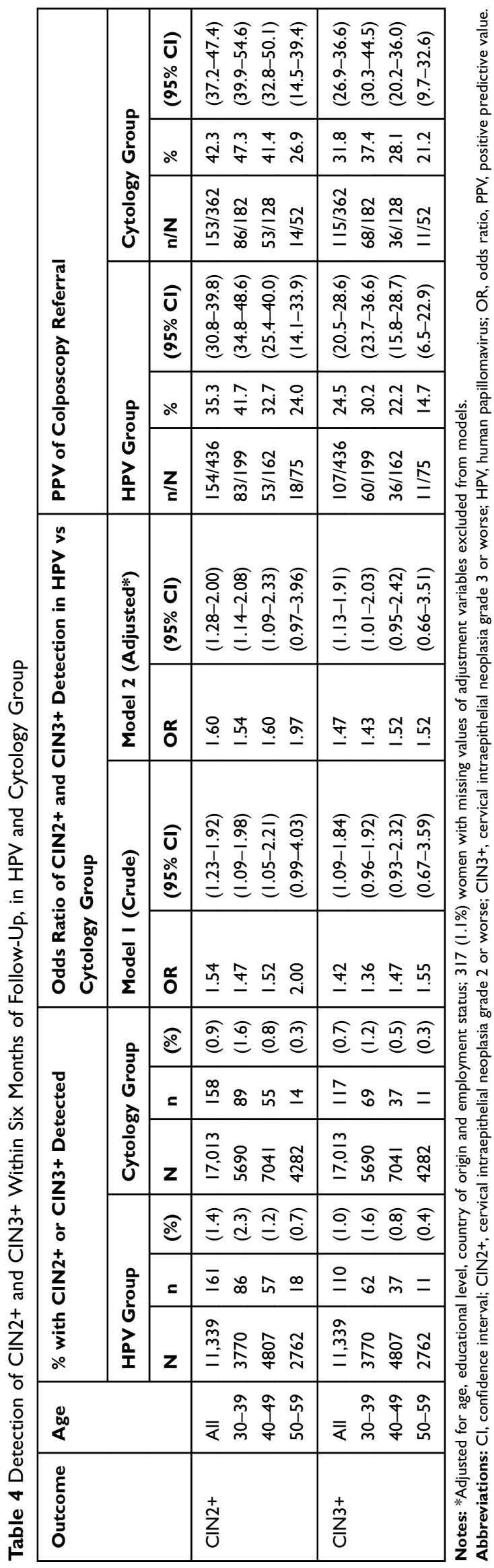

a conservative strategy, where women with LSIL were only referred to colposcopy if they were HPV mRNA positive. This is consistent with Danish guidelines ${ }^{29}$ which recommend HPV mRNA testing for LSIL triage, because it has been shown that HPV mRNA testing of LSIL provides higher specificity and lower referral rates than HPV DNA testing of LSIL, with similar sensitivity. ${ }^{40}$ These choices concerning screening algorithms have likely augmented the difference in referrals between HPV and cytology screening in our study. Furthermore, the referral rate in our study reflects a baseline round of HPV testing. In the Canadian FOCAL trial ${ }^{2}$ and in Italian $^{21,22}$ and English ${ }^{12}$ pilot implementations, immediate referral rates at the second round of HPV screening were markedly lower than in the first round, likely reflecting that prevalent HPV infections are "screened out" in the first round. Therefore, we expect the referral rate to decrease in the next round of HPV screening in Denmark.

We also found that HPV-testing of clinician-taken samples did not affect the attendance rate. In line with this, most previous implementation studies found similar ${ }^{18,19,21,22}$ participation in HPV and cytology-based screening. Accordingly, a Norwegian survey found that women's intentions to participate in screening did not differ between women invited for HPV- or cytology-based screening. ${ }^{41}$ In the Netherlands, participation decreased slightly when HPV-based screening was introduced, but the authors argued that this was likely due to concurrent changes in the invitation procedure. ${ }^{28}$ While it is reassuring that in our study introduction of HPV screening did not decrease attendance, the participation rates in both groups of our study $(\approx 70 \%$ after 1 year) were lower than the national target for the screening program (75\% after 1 year). ${ }^{32}$ Thus, increasing participation remains an important priority for the Danish program. ${ }^{30}$

A further finding of our study was that HPV-based screening resulted in fewer unsatisfactory screening tests $(0.1 \%)$ than cytology $(0.7 \%)$. During recent years, substantial efforts have been made in Denmark to decrease the rate of unsatisfactory smears, including introduction of liquidbased cytology, instruction of general practitioners with high unsatisfactory rates, and annual feedback at regional and hospital levels. ${ }^{32}$ This has led to a marked decrease in the national proportions of unsatisfactory smears from $3.1 \%$ in $2009^{42}$ to $0.7 \%$ in $2017,,^{32}$ consistent with the proportion in the cytology group in our study. Despite this, HPV screening still performed better than cytology. Since the proportions of unsatisfactory cytology in some screening programs may be as high as $3-10 \%,{ }^{43}$ the gains from introducing HPV screening in such settings may be even higher. 
This implementation study was embedded into the routine screening program in a large Danish pathology department, allowing us to assess the real-world clinical performance of HPV-based screening. The strengths of the study include the population-based design and the follow-up in a nationwide pathology register with virtually $100 \%$ coverage, meaning that we had information on all CIN2+ cases diagnosed in Denmark. A potential limitation is that allocation to screening method was based on the area of residence instead of randomization. However, we compared the HPV and cytology groups by retrieving extensive, individual-level information from nationwide registers of high validity. There were no marked differences in sociodemographic characteristics or previous CIN2+-history between the two groups, and adjustment for these factors did not change our results. Another limitation is that we had only 6 months of follow-up, meaning that we could not take into account the results of clinical management after 12-month repeat screening. In the HPV arm, $5 \%$ of women were referred to repeat screening, and both referral rates and $\mathrm{CIN} 2+$ detection are expected to increase when results of this early recall are available. . $2,21,22,24,25$

In conclusion, the results of this large pilot implementation confirm that HPV-based screening provides greater detection of high-grade CIN and cervical cancer than cytology-based screening. These results support ongoing efforts to implement HPV-based screening in Denmark ${ }^{30}$ and elsewhere. Although referral rates were high in this initial screening round, referrals are expected to decrease in subsequent rounds. Furthermore, several triage methods in HPV-positive women are currently being evaluated, including p16/Ki-67 dual-staining, host or viral methylation and extended HPV genotyping. ${ }^{44}$ Such triage methods may further optimize the management of HPV-positive women, thereby taking full advantage of the benefits of HPV-based screening while minimizing potential harms.

\section{Abbreviations}

AIS, adenocarcinoma in situ; ASCUS, atypical squamous cells of undetermined significance; CI, confidence interval; $\mathrm{CIN}$, cervical intraepithelial neoplasia; $\mathrm{CIN} 2+$, cervical intraepithelial neoplasia grade 2 or worse; $\mathrm{CIN} 3+$, cervical intraepithelial neoplasia grade 2 or worse; DNA, deoxyribonucleic acid; HPV, human papillomavirus; HSIL, highgrade squamous intraepithelial lesion; IQR, interquartile range; LSIL, low-grade squamous intraepithelial lesion; mRNA, messenger ribonucleic acid; OR, odds ratio, PPV, positive predictive value.

\section{Acknowledgments}

Interim findings of this paper were presented in part as oral presentations at the 32nd International Papillomavirus Conference (Sydney, Australia, October 2018); the 2018 EUROGIN conference (Lisbon, Portugal, December 2018); and the 2019 EUROGIN conference (Monaco, December 2019).

\section{Author Contributions}

MW, SKK, LTT, DOE and CM initiated, planned and designed the study. MW, SKK and LTT obtained funding. MW organized the implementation of HPV-based screening. DOE was responsible for HPV testing and other laboratory procedures. LTT performed registry linkages, data management and statistical analyses. KF assisted with the statistical analyses. LTT wrote the first draft of the manuscript. All authors contributed to analysis and interpretation of results, drafting and revising the article, gave final approval of the version to be published, and agree to be accountable for all aspects of the work.

\section{Funding}

This study was funded by the Lundbeck Foundation (grant no. R287-2018-1454), the Mermaid project (Mermaid 2), and by Lillebaelt Hospital, Region of Southern Denmark.

\section{Disclosure}

HPV tests for this study were provided at reduced cost by Roche. Louise T. Thomsen reports grants from Lundbeck Foundation during the conduct of the study. Susanne K. Kjær has previously received speakers' fees, advisory board fees and a research grant from Merck, who is the manufacturer of a vaccine against HPV. All other authors declare no potential competing interests.

\section{References}

1. Vaccarella S, Lortet-Tieulent J, Plummer M, Franceschi S, Bray F. Worldwide trends in cervical cancer incidence: impact of screening against changes in disease risk factors. Eur J Cancer. 2013;49:3262-3273. doi:10.1016/j.ejca.2013.04.024

2. Ogilvie GS, van Niekerk D, Krajden M, et al. Effect of screening with primary cervical HPV testing vs cytology testing on high-grade cervical intraepithelial neoplasia at 48 months: the HPV FOCAL randomized clinical trial. JAMA. 2018;320:43-52. doi:10.1001/jama.2018.7464

3. Leinonen MK, Nieminen $\mathrm{P}$, Lonnberg $\mathrm{S}$, et al. Detection rates of precancerous and cancerous cervical lesions within one screening round of primary human papillomavirus DNA testing: prospective randomised trial in Finland. BMJ. 2012;345:e7789. doi:10.1136/ bmj.e 7789 
4. Ronco G, Giorgi-Rossi P, Carozzi F, et al. Efficacy of human papillomavirus testing for the detection of invasive cervical cancers and cervical intraepithelial neoplasia: a randomised controlled trial. Lancet Oncol. 2010;11:249-257. doi:10.1016/S1470-2045(09)70360-2

5. Mayrand MH, Duarte-Franco E, Rodrigues I, et al. Human papillomavirus DNA versus Papanicolaou screening tests for cervical cancer. N Engl J Med. 2007;357:1579-1588. doi:10.1056/NEJMoa071430

6. Bulkmans NW, Berkhof J, Rozendaal L, et al. Human papillomavirus DNA testing for the detection of cervical intraepithelial neoplasia grade 3 and cancer: 5-year follow-up of a randomised controlled implementation trial. Lancet. 2007;370:1764-1772. doi:10.1016/ S0140-6736(07)61450-0

7. Sankaranarayanan R, Nene BM, Dinshaw KA, et al. A cluster randomized controlled trial of visual, cytology and human papillomavirus screening for cancer of the cervix in rural India. Int $J$ Cancer. 2005;116:617-623. doi:10.1002/(ISSN)1097-0215

8. Naucler P, Ryd W, Tornberg S, et al. Human papillomavirus and Papanicolaou tests to screen for cervical cancer. $N$ Engl J Med. 2007;357:1589-1597. doi:10.1056/NEJMoa073204

9. Ronco G, Dillner J, Elfstrom KM, et al. Efficacy of HPV-based screening for prevention of invasive cervical cancer: follow-up of four European randomised controlled trials. Lancet. 2014;383:524-532. doi:10.1016/S0140-6736(13)62218-7

10. Arbyn M, Ronco G, Anttila A, et al. Evidence regarding human papillomavirus testing in secondary prevention of cervical cancer. Vaccine. 2012;30(Suppl 5):F88-F99. doi:10.1016/j.vaccine.2012.06.095

11. Polman NJ, Snijders PJF, Kenter GG, Berkhof J, Meijer C. HPVbased cervical screening: rationale, expectations and future perspectives of the new Dutch screening programme. Prev Med. 2019;119:108-117. doi:10.1016/j.ypmed.2018.12.021

12. Rebolj M, Rimmer J, Denton K, et al. Primary cervical screening with high risk human papillomavirus testing: observational study. BMJ. 2019;364:1240. doi:10.1136/bmj.1240

13. Swedish National Board of Health and Welfare (Socialstyrelsen). Screening for Cervical Cancer. Recommendation and Evidence Base [in Swedish]. Stockholm, Sweden: Socialstyrelsen; 2015. Available from: https://www.socialstyrelsen.se/globalassets/share point-dokument/artikelkatalog/nationella-screeningprogram/20156-39.pdf. Accessed November 6, 2019.

14. Norwegian Cancer Registry (Kreftregisteret). HPV in Primary Screening [in Norwegian]. Oslo, Norway: Kreftregisteret; 2019. Available from https://www.kreftregisteret.no/screening/livmorhalspro grammet/Helsepersonell/screeningstrategi-og-nasjonale-retningslinjer /HPV-i-primarscreening/. Accessed November 6, 2019.

15. Ronco G, Giorgi Rossi P, Giubilato P, et al. A first survey of HPV-based screening in routine cervical cancer screening in Italy. Epidemiol Prev. 2015;3(Suppl 1):77-83.

16. Australian Government, Department of Health. National Cervical Screening Program. Canberra, Australia: Australian Government Department of Health; 2019. Available from: http://www.cancerscreen ing.gov.au/internet/screening/publishing.nsf/Content/cervical-screening -1. Accessed November 6, 2019.

17. National Screening Unit, New Zealand. HPV Primary Screening. Auckland, New Zealand: National Screening Unit of New Zealand; 2017. Available from: https://www.nsu.govt.nz/healthprofessionals/national-cervical-screening-programme/hpv-primary -screening. Accessed November 6, 2019.

18. Veijalainen O, Kares S, Kujala P, et al. Implementation of HPV-based cervical cancer screening in an organised regional screening programme: 3 years of experience. Cytopathology. 2019;30:150-156. doi:10.1111/cyt.2019.30.issue-2

19. Lamin H, Eklund C, Elfstrom KM, et al. Randomised healthcare policy evaluation of organised primary human papillomavirus screening of women aged 56-60. BMJ Open. 2017;7:e014788. doi:10.1136/ bmjopen-2016-014788
20. Zorzi M, Frayle H, Rizzi M, et al. A 3-year interval is too short for re-screening women testing negative for human papillomavirus: a population-based cohort study. BJOG. 2017;124:1585-1593. doi:10.1111/1471-0528.14575

21. Pasquale L, Giorgi Rossi P, Carozzi F, et al. Cervical cancer screening with HPV testing in the Valcamonica (Italy) screening programme. J Med Screen. 2015;22:38-48. doi:10.1177/0969141314561707

22. Passamonti B, Gustinucci D, Giorgi Rossi P, et al. Cervical human papillomavirus (HPV) DNA primary screening test: results of a population-based screening programme in central Italy. $J$ Med Screen. 2017;24:153-162. doi:10.1177/0969141316663580

23. Maggino T, Sciarrone R, Murer B, et al. Screening women for cervical cancer carcinoma with a HPV mRNA test: first results from the Venice pilot program. Br J Cancer. 2016;115:525-532. doi:10.1038/bjc.2016.216

24. Del Mistro A, Frayle H, Ferro A, et al. Cervical cancer screening by high risk HPV testing in routine practice: results at one year recall of high risk HPV-positive and cytology-negative women. J Med Screen. 2014;21:30-37. doi:10.1177/0969141314522219

25. Zorzi M, Del Mistro A, Farruggio A, et al. Use of a high-risk human papillomavirus DNA test as the primary test in a cervical cancer screening programme: a population-based cohort study. BJOG. 2013;120:1260-1267. doi:10.1111/1471-0528.12272

26. Confortini M, Giorgi Rossi P, Barbarino P, Passarelli AM, Orzella L, Tufi MC. Screening for cervical cancer with the human papillomavirus test in an area of central Italy with no previous active cytological screening programme. J Med Screen. 2010;17:79-86. doi:10.1258/jms.2010.009092

27. Gultekin M, Zayifoglu Karaca M, Kucukyildiz I, et al. Initial results of population based cervical cancer screening program using HPV testing in one million Turkish women. Int J Cancer. 2018;142:1952-1958. doi:10.1002/ijc.v142.9

28. Aitken CA, van Agt HME, Siebers AG, et al. Introduction of primary screening using high-risk HPV DNA detection in the Dutch cervical cancer screening programme: a population-based cohort study. $B M C$ Med. 2019;17:228. doi:10.1186/s12916-019-1460-0

29. Danish National Board of Health. Screening Against Cervical CancerRecommendations [in Danish]. Copenhagen, Denmark: National Board of Health; 2012. Available from: https://www.sst.dk/ /media/ B1211EAFEDFB47C5822E883205F99B79.ashx. Accessed November $6,2019$.

30. Danish National Board of Health. Screening Against Cervical CancerRecommendations [in Danish]. Copenhagen, Denmark: National Board of Health; 2018. Available from: https://www.sst.dk/da/sygdom-og-behand ling/screening/ /media/5466AB0B06184ED0969BC31DA397610D. ashx. Accessed November 6, 2019.

31. Bjerregaard B, Larsen OB. The Danish Pathology Register. Scand J Public Health. 2011;39(Suppl):72-74. doi:10.1177/1403494810393563

32. Danish Quality Database for Cervical Cancer Screening. Annual Report 2017 [in Danish] Vejle, Denmark: Danish Quality Database for Cervical Cancer Screening; 2018. Available from: https://www.sundhed.dk/con tent/cms/82/4682_dkls-livmoderhalsscreening-aarsrapport-2017_ende lig.pdf. Accessed November 6, 2019.

33. Nohr B, Frydshou D, Khan HS, et al. Danish Society of Obstetrics and Gynecology Clinical Guidelines. Diagnosis, Treatment and Control of Cervical Dysplasia [In Danish]. Copenhagen, Denmark: Danish Society of Obstetrics and Gynecology; 2013. Available from: http://gynobsguide line.dk/hindsgavl/Cervixdysplasi2012.pdf. Accessed November 62019.

34. Jensen VM, Rasmussen AW. Danish Education Registers. Scand J Public Health. 2011;39 7(Suppl):91-94.

35. Petersson F, Baadsgaard M, Thygesen LC. Danish registers on personal labour market affiliation. Scand J Public Health. 2011;39 7 (Suppl):95-98. doi:10.1177/1403494811408483

36. Kildemoes HW, Sorensen HT, Hallas J. The Danish National Prescription Registry. Scand J Public Health. 2011;39 7(Suppl):38-41. doi:10.1177/1403494810394717 
37. Andersen JS, Olivarius N, Krasnik A. The Danish National Health Service Register. Scand J Public Health. 2011;39 7(Suppl):34-37. doi:10.1177/1403494810394718

38. Kyrgiou M, Athanasiou A, Paraskevaidi M, et al. Adverse obstetric outcomes after local treatment for cervical preinvasive and early invasive disease according to cone depth: systematic review and meta-analysis. BMJ. 2016;354:i3633. doi:10.1136/bmj.i3633

39. Huh WK, Ault KA, Chelmow D, et al. Use of primary high-risk human papillomavirus testing for cervical cancer screening: interim clinical guidance. J Low Genit Tract Di. 2015;19:91-96. doi:10.1097/ LGT.0000000000000103

40. Arbyn M, Roelens J, Cuschieri K, et al. The APTIMA HPV assay versus the Hybrid Capture 2 test in triage of women with ASC-US or LSIL cervical cytology: a meta-analysis of the diagnostic accuracy. Int J Cancer. 2013;132:101-108. doi:10.1002/ijc.27636
41. Burger EA, Nygard M, Gyrd-Hansen D, Moger TA, Kristiansen IS. Does the primary screening test influence women's anxiety and intention to screen for cervical cancer? A randomized survey of Norwegian women. BMC Public Health. 2014;14:360. doi:10.1186/ 1471-2458-14-360

42. Danish Quality Database for Cervical Cancer Screening. Annual Report 2010 [in Danish]. Copenhagen, Denmark: Danish Quality Database for Cervical Cancer Screening; 2010.

43. Fontaine D, Narine N, Naugler C. Unsatisfactory rates vary between cervical cytology samples prepared using ThinPrep and SurePath platforms: a review and meta-analysis. BMJ Open. 2012;2(2): e000847. doi:10.1136/bmjopen-2012-000847

44. Cuschieri K, Ronco G, Lorincz A, et al. Eurogin roadmap 2017: triage strategies for the management of HPV-positive women in cervical screening programs. Int J Cancer. 2018;143:735-745. doi:10.1002/ijc.31261

\section{Publish your work in this journal}

Clinical Epidemiology is an international, peer-reviewed, open access, online journal focusing on disease and drug epidemiology, identification of risk factors and screening procedures to develop optimal preventative initiatives and programs. Specific topics include: diagnosis, prognosis, treatment, screening, prevention, risk factor modification,

Submit your manuscript here: https://www.dovepress.com/clinical-epidemiology-journal systematic reviews, risk \& safety of medical interventions, epidemiology \& biostatistical methods, and evaluation of guidelines, translational medicine, health policies \& economic evaluations. The manuscript management system is completely online and includes a very quick and fair peer-review system, which is all easy to use. 